\title{
Patient-Reported Fatigue Is Associated with Poor Energy Intake and Readmission to Hospital
}

\author{
Jette Lindegaard Pedersen1 ${ }^{10}$, Preben Ulrich Pederen², Else Marie Damsgaard1 \\ ${ }^{1}$ Department of Geriatrics, Aarhus University Hospital, Aarhus, Denmark \\ ${ }^{2}$ Center of Clinical Guidelines-Clearing House, Department of Health Science and Technology, Aalborg University, \\ Aalborg, Denmark \\ Email:jetpeder@rm.dk
}

How to cite this paper: Pedersen, J.L., Pederen, P.U. and Damsgaard, E.M. (2020) Patient-Reported Fatigue Is Associated with Poor Energy Intake and Readmission to Hospital. Health, 12, 253-269.

https://doi.org/10.4236/health.2020.123021

Received: February 4, 2020

Accepted: March 21, 2020

Published: March 24, 2020

Copyright $\odot 2020$ by author(s) and Scientific Research Publishing Inc. This work is licensed under the Creative Commons Attribution International License (CC BY 4.0).

http://creativecommons.org/licenses/by/4.0/

\begin{abstract}
Objective: To investigate patient-reported factors those promote or inhibit food intake in older people after discharge from hospital. Background: Disease-related malnutrition leads to poor appetite, decreased food intake and affects convalescence negatively. Design: Secondary analysis of two intervention groups from an RCT. Methods: 111 older adults received nutritional follow-up one, two and four weeks after discharge. Self-reported food intake was classified as adequate $(\mathrm{AQ})$ or inadequate (IAQ) energy intake two weeks after discharge. Data on inhibitory and promoting factors, body weight, ADL-function, readmission and mortality were analysed and comparison made between AQ and IAQ groups. Results: More IAQ participants reported fatigue and eating all meals alone. All participants lost body weight, but more IAQ participants lost body weight. More IAQ participants were readmitted to hospital 30 days after discharge. Conclusion: "Fatigue" and "eating all meals alone" affect food intake negatively, leading to loss of body weight and readmission to hospital.
\end{abstract}

\section{Keywords}

Patient-Reported Nutritional Problems, Malnutrition, Fatigue, Eating Alone

\section{Introduction}

Disease-related malnutrition leads to poor appetite and decreased food intake, which affects older people's convalescence negatively, after acute disease and hospital discharge. Poor nutritional status at admission often deteriorates further during hospital stay [1]. As the length of hospital stay is being reduced all over the 
world, many older people are still malnourished or at risk of malnutrition after discharge from hospital [2] [3], because nutritional treatment requires long-term interventions.

\section{Background}

Aging per se affects appetite and food intake in several physiological ways, such as delayed gastric emptying, leading to less hunger and increase in fullness [4]; reduced appetite [5]; decline in smell and taste senses; and dental and chewing problems which influence the quality of food choices and lead to food avoidance and discomfort [6]. Barriers to decreased food intake are multi-faceted, and include social and environmental factors such as eating alone, and individual factors such as fatigue, sadness and gastrointestinal problems [7] [8]. Older individuals consume less food, have smaller meals, and drink less between meals compared with younger individuals [6]. Acute and chronic disease further aggravates nutritional status with increased metabolic activity and further decreased appetite and food intake [9]. Unlike their younger counterparts, older individuals do not spontaneously regain their appetite or resume previous food intake after recovery [10].

Very little research focuses on barriers to food intake from the patient's perspective. In order to understand the obstacles that older individuals face after disease and discharge from hospital, we wanted to identify inhibiting and promoting factors to food intake from the patient's perspective and investigate their consequences.

The purpose of this study was to investigate the effect of patient-reported factors that inhibit or promote food intake. Furthermore, we wanted to compare the effect of adequate or inadequate energy intake two weeks after discharge, on body weight, activities of daily living (ADL function), readmission and mortality.

First, confirm that you have the correct template for your paper size. This template has been tailored for output on the custom paper size $(21 \mathrm{~cm} \times 28.5 \mathrm{~cm})$.

\section{Methods}

Data in this study include participants from two intervention groups in an earlier randomised study on nutritional follow-up after discharge.

\subsection{Setting and Samples}

Patients were recruited from the Department of Geriatrics, Aarhus University Hospital, Denmark, between May 2011 and October 2013. The inclusion criteria were: 1) malnourishment or risk of malnutrition; 2) 75 years or older; and 3) living independently and alone in the area served by the hospital. Nursing home residents and patients who suffered from terminal illnesses or cognitive impairment were excluded. The Mini Nutritional Assessment (MNA) instrument was used to identify malnourished patients $(\mathrm{MNA}<17)$ and patients at risk of malnutrition $(17 \leq \mathrm{MNA}<24)[11][12]$. 
At discharge, the participants received an individualised diet plan which would cover the daily energy needs according to the Nordic Nutrition Recommendations for $>75$ years of age [13]. The individual diet plan included three daily meals, three between-meal snacks and supplements, as well as instructions for implementing the plan according to the participant's individual preferences. Patients were contacted three times after discharge from hospital by a clinical dietitian, who provided nutritional counselling, either during a home visit (home visit group) or telephone consultation (telephone group). The intervention started week one after discharge, when the participants was well-established at home and receptive to the intervention, was resumed after two weeks, to keep the intervention on track, and was completed after four weeks.

The clinical dietitian used a diversity of strategies to encourage participants to change unfavourable eating and meal habits to healthier nutritional behaviours. The patient's home carer was invited to participate in the nutritional counselling. The randomization and intervention is described elsewhere [14].

\subsection{Measurements}

At each contact, the participants reported to the dietitian, if they had followed the diet plan fully, partly or not at all. To follow the diet plan was defined to eat all meals in the diet plan. This was registered as adequate energy intake. Partly followed and not following the diet plan were registered as inadequate energy intake. The participants were grouped according to adequate (AQ) or inadequate (IAQ) energy intake at week two after discharge from hospital. At each contact, the clinical dietitian interviewed the patient and made observations, guided by a questionnaire, to identify inhibiting and restraining elements and conditions that might contribute to reduced intake of food and fluid, as well as health-promoting behaviours and conditions that might improve intake of food and fluid. The questionnaire included the following items: 1) Status of the nutritional situation since discharge/previous session, including the participants' specification of nutritional intake. Is the intake consistent with the diet plan? Is the intake more or less, or does the participant use meal replacements? 2) Identify inhibiting and restraining elements, and conditions that contribute to the reduced intake of food and fluid. Identify health-promoting behavior, and conditions that contribute to the improved intake of food and fluid. 3) Support health promoting behavior, and encourage the participant to overcome negative conditions. 4) In cooperation with the participant, adjust the nutrition plan (e.g. what, how, and when to intake food and fluid). 5) Encourage, support, and stimulate the participant and the home carer to follow the diet plan. The questionnaire specified the presence of gastrointestinal problems, eating all meals alone, sadness and fatigue. Furthermore, the participants could describe additional factors that promote or inhibit food intake (see Appendix).

\subsection{Outcomes}

Baseline characteristics were obtained from the patients' records at discharge. 
Patients reported data on dietary intake (AQ or IAQ energy intake) as well as inhibiting and promoting factors to food intake. The information was collected by the clinical dietitian at each contact.

Body weight, Modified Barthel-100 index (MBI), handgrip strength, Geriatric Depression Score (GDS) and Avlund mobility-tiredness Scale were measured in the participants' homes by a research assistant the day after discharge and again eight weeks later.

Body weight was measured using the same scales for all measurements. Weight changes by 0.5 kilo or more were registered as weight gain or weight loss. MBI is a 10-item instrument that provides a score of basic daily activities (feeding, bathing, grooming, dressing, bowels, bladder, toilet use, transfer, mobility, and climbing stairs). The scores range from 0 - 100, with a higher score indicating greater independence [15]. Handgrip strength measures strength in the upper limb muscles, and is determined using Jamar handgrip dynamometry in a sitting position, and with the dominant hand and the elbow flexed at a $90^{\circ}$ angle. The highest of 3 readings is recorded [16]. GDS is a fifteen-item instrument designed to assess emotional well-being in the older population [17]. The scores range from 0 to 15 , where 0 points indicate no depression, and 15 indicate severe depression. A Danish version was validated, and the test concluded that the GDS, performed as an interview, is suitable for detecting depression among the home-dwelling, cognitively intact older adults (70 years or older) [18]. Avlund mobility-tiredness scale is a six-item, functional ability scale that evaluates fatigue related to mobility (transfer, walking indoors, going outdoors, walking outdoors in nice weather, walking outdoors in poor weather, and climbing stairs) [19]. Items managed without fatigue count as two points, items managed with fatigue count as one point, and items that the older adults cannot manage count as zero. The maximum score of twelve points indicates no fatigue, whereas zero points indicate insuperable fatigue.

Data on readmission to hospital and mortality at 30 and 90 days after discharge were obtained from the electronic patient records.

The two groups (AQ and IAQ energy intake at week two) were compared in relation to patient-reported data; changes in outcome measures between discharge and eight weeks after (body weight, Barthel-100, handgrip strength, GDS, and Avlund mobility-tiredness), and readmissions to hospital and mortality at 30 and 90 days after discharge.

\subsection{Statistics}

Continuous variables are presented as means with standard deviations (SD) for normally distributed variables and median with inter-quartile ranges (IQR) for non-normally distributed variables. Dichotomous variables are presented with numbers and percentage. The variable Barthel-100 was not normally distributed and therefore analysed using Mann Whitney U test. All other continuous variables were analysed using Student's t-test. Dichotomous variables were analysed using Person's chi-square test or Fisher's exact test. Inhibitory factors to 
food intake week one and two were entered into a logistic regression model to estimate the risk of reduced energy intake week two and four after discharge. Odds Ratios (OR) is presented with $95 \%$ confidence intervals. Subsequently, the models were checked for proportionality by log-log plots. The risk of readmission to hospital and mortality at 30 and 90 days after discharge were analysed using the Cox proportional regression model to estimate hazard ratio (HR) with 95\% CIs. Subsequently, the OR and HR estimates were adjusted for morbidity. Furthermore, readmissions and mortality were presented as numbers and percentages. All statistical analyses were performed using Stata 15 with a level of significance of 0.05 or less.

\subsection{Ethics}

Informed written consent was obtained from the participants before hospital discharge. The study was approved by the Danish Data Protection Agency, journal no. 2014-41-3221, and the Ethical Committee of Central Denmark Region, journal no. M-20100201. Trial registration: Clinical.Trials.gov, NCT01345032.

\section{Results}

At discharge from hospital, the study included 141 participants. Data on 121 participants were collected at one week after discharge; data on 111 participants at two weeks after discharge and data on 99 participants at four weeks after discharge. Among the 141 participants who were included at discharge from hospital, 42 (30\%) did not complete the full program of three nutritional counselling sessions. The reasons for not completing the full intervention program were death, re-hospitalisation, transfer to nursing home, fatigue, pain or desire to stop the intervention. All home carers were invited to participate in the nutritional counselling; 31 (26\%) participated at one week after discharge, 13 (12\%) at two weeks after and $6(6 \%)$ at four weeks after discharge.

At the first week after discharge, 32 participants (26\%) achieved adequate energy intake; at the second week, 48 (42\%) achieved adequate energy intake, and at the fourth week, 51 participants (52\%) achieved adequate energy intake. Twenty-five participants (21\%) reported adequate energy intake during the whole period, 41 (34\%) had inadequate intake in the whole period, 22 (18\%) dropped out, and 33 (27\%) switched between adequate and inadequate energy intake during the intervention period. The flow of the participants' adequate or inadequate energy intake is shown in Figure 1.

Table 1 shows the baseline characteristics at discharge from hospital, with participants grouped according to adequate (AQ) or inadequate (IAQ) food intake two weeks after discharge.

\subsection{Patient-Reported Outcome Measures}

Two weeks after discharge, the IAQ group more frequently reported gastro-intestinal problems, fatigue, sadness and eating all meals alone than the AQ group (Table 2). 
Table 1. Baseline characteristics at discharge from hospital. Participants are grouped according to adequate (AQ) or inadequate (IAQ) food intake two weeks after discharge.

\begin{tabular}{|c|c|c|c|}
\hline & \multicolumn{3}{|c|}{ Energy intake at week two after discharge } \\
\hline & $\begin{array}{c}\text { Adequate } \\
(\mathrm{n}=48)\end{array}$ & $\begin{array}{l}\text { Inadequate } \\
\quad(n=63)\end{array}$ & p-value \\
\hline Mean age, years (SD) & $85.5(0.8)$ & $85.6(0.7)$ & 0.44 \\
\hline Women, n (\%) & $40(83)$ & $52(83)$ & 0.91 \\
\hline Comorbidity, $\mathrm{n}(\%)^{\#}$ & & & 0.29 \\
\hline Low & $24(50)$ & $33(52)$ & \\
\hline Moderate & $19(40)$ & $28(45)$ & \\
\hline Severe & $5(10)$ & $2(3)$ & \\
\hline Reason for admission to hospital, $\mathrm{n}(\%)$ & & & 0.80 \\
\hline Hip fracture & $24(50)$ & $30(48)$ & \\
\hline Medical diseases & $24(50)$ & $33(52)$ & \\
\hline Barthel-100 score, median [IQR] & $83[78 ; 88]$ & $81[75 ; 85]$ & 0.41 \\
\hline Length of stay at hospital, days (SD) & $7.5(3.5)$ & $8.2(4.8)$ & 0.44 \\
\hline Weight, kg (SD) & $63.5(2.3)$ & $62.8(1.8)$ & 0.46 \\
\hline Nutritional status ${ }^{*}$ & & & 0.34 \\
\hline $\mathrm{MNA}<17, \mathrm{n}(\%)$ & $17(35)$ & $28(44)$ & \\
\hline MNA: $17-23.5, \mathrm{n}(\%)$ & $31(65)$ & $35(56)$ & \\
\hline Dental status & & & 0.90 \\
\hline Original teeth, n (\%) & $12(25)$ & $18(29)$ & \\
\hline Partial dentures, $\mathrm{n}(\%)$ & $20(42)$ & $24(38)$ & \\
\hline Complete dentures, $\mathrm{n}(\%)$ & $16(33)$ & $21(33)$ & \\
\hline \multicolumn{4}{|l|}{ Intervention form } \\
\hline Home visit, n (\%) & $28(48)$ & $30(52)$ & \multirow{2}{*}{0.26} \\
\hline Telephone contact, $\mathrm{n}(\%)$ & $20(38)$ & $33(62)$ & \\
\hline \multicolumn{4}{|l|}{ Help after discharge } \\
\hline Help from community nurse, $\mathrm{n}(\%)$ & $31(65)$ & $42(66)$ & 0.57 \\
\hline Help from home care, n (\%) & & & 0.56 \\
\hline Daily & $42(88)$ & $55(87)$ & \\
\hline Weekly & $3(6)$ & $2(3)$ & \\
\hline No home care & $3(6)$ & $6(10)$ & \\
\hline Daily nutritional support & $35(78)$ & $50(86)$ & 0.26 \\
\hline Meals on wheels & $31(65)$ & $51(81)$ & 0.05 \\
\hline
\end{tabular}

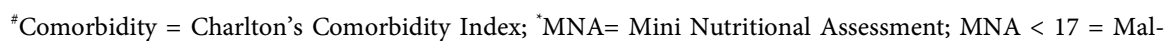
nourished; MNA 17 - 23.5 = Risk of malnutrition. 


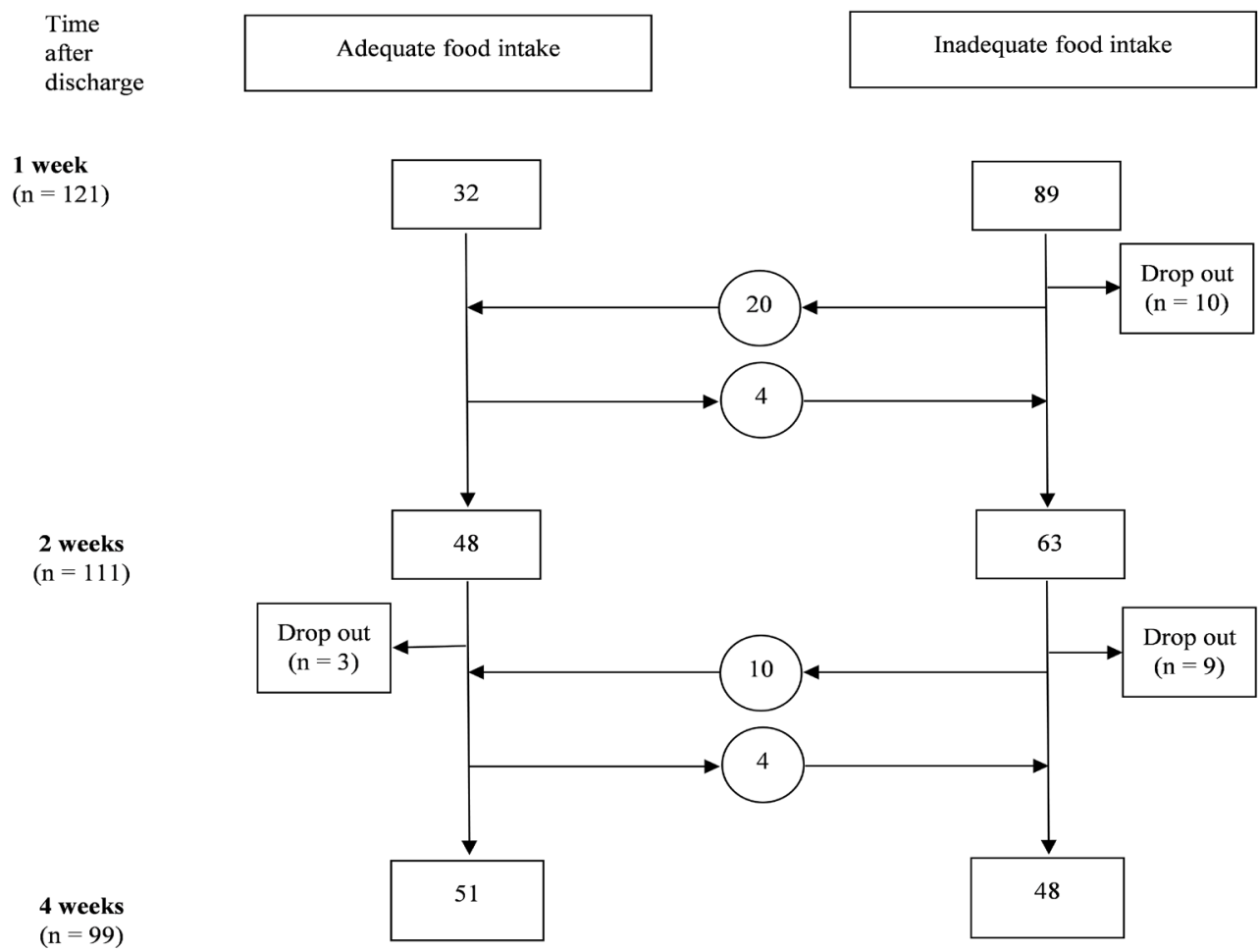

Figure 1. Flow of the patients' adequate (AQ) or inadequate (IAQ) food intake, 1, 2 and 4 weeks after discharge from hospital.

Table 2. Patient-reported factors affecting food intakegrouped according to adequate (AQ) or inadequate (IAQ) food intake two weeks after discharge $(\mathrm{n}=111)$.

\begin{tabular}{cccc}
\hline & $\begin{array}{c}\text { Adequate energy } \\
\text { intake }(\mathbf{n}=\mathbf{4 8})\end{array}$ & $\begin{array}{c}\text { Inadequate energy } \\
\text { intake }(\mathbf{n}=63)\end{array}$ & p-value \\
\hline Gastrointestinal problems, n (\%) & $5(11)$ & $23(37)$ & 0.002 \\
Fatigue, n (\%) & $19(40)$ & $42(67)$ & 0.004 \\
Sadness, n (\%) & $7(15)$ & $20(32)$ & 0.04 \\
Eating all meals alone, n (\%) & $24(51)$ & $51(82)$ & 0.001 \\
Other inhibiting factors, n (\%) & $18(38)$ & $32(51)$ & 0.16 \\
Promoting factors, n (\%) & $48(100)$ & $56(92)$ & 0.02 \\
\hline
\end{tabular}

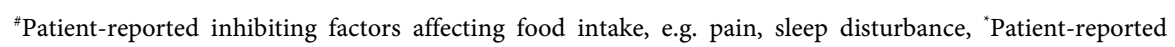
promoting factors affecting food intake, e.g. drinking additional oral nutritional supplements (ONS), eating with family or friends, visiting neighbours, preparing meals, going for a walk, a good night's sleep.

The occurrence of patient-reported fatigue week one and two after discharge was associated with decreased food intake week two and four (OR 2.4, 95\% CI: $1.1-5.4 ; \mathrm{p}=0.03)$. Eating all meals alone week one and two, was also associated with decreased food intake week two and four (OR 3.0, 95\% CI: $1.4-6.5 ; \mathrm{p}=$ 0.006). Gastrointestinal problems and sadness week one and two affected food intake week two and four (OR 3.1, 95\% CI: 0.9 - 11.6; $\mathrm{p}=0.08$ and OR 2.7, 95\% CI: $0.8-8.5 ; p=0.09$, respectively), but not significantly. No difference was detected between crude estimates and estimates adjusted for morbidity. 


\subsection{Body Weight and ADL}

Both groups lost body weight between discharge and eight weeks after $(\mathrm{AQ}=$ mean $-0.5 \mathrm{~kg}, \mathrm{IAQ}=$ mean $-1.6 \mathrm{~kg}, \mathrm{p}=0.09$ ). More patients in the IAQ group lost body weight (55\%) than in the AQ group (38\%) ( $\mathrm{p}=0.03)$.

Median ADL improved in both groups. In the AQ group, the Barthel-100 score increased by 8 points; in the IAQ group, it increased by 5 points, but no significant difference between groups was detected $(p=0.22)$. ADL deteriorated in 3 (6\%) AQ patients and $11(17 \%)$ IAQ patients $(\mathrm{p}=0.06)($ Table 3$)$.

\subsection{Readmission to Hospital}

The IAQ group had a higher risk of readmission to hospital than the AQ group within 30 days after discharge ( $\mathrm{HR}=4.5$; 95\% CI: $1.01-20.68, \mathrm{p}=0.05$ ) (Figure 2 ), but not at 90 days after discharge ( $\mathrm{HR}=1.6,95 \% \mathrm{CI}$ : $0.7-3.6, \mathrm{p}=0.25)$. No difference was detected between crude and adjusted estimates (Table 4).

Table 3. Change in outcome between discharge and 8 weeks follow-up. Participants are grouped according to adequate (AQ) or inadequate (IAQ) energy intake two weeks after discharge $(n=111)$

\begin{tabular}{|c|c|c|c|}
\hline & $\begin{array}{l}\text { Adequate energy } \\
\text { intake at week } 2 \\
(n=48)\end{array}$ & $\begin{array}{l}\text { Inadequate energy } \\
\text { intake at week } 2 \\
(n=63)\end{array}$ & p-value \\
\hline Weight, mean change kg. (SD) & $-0.5(0.4)$ & $-1.6(0.4)$ & 0.09 \\
\hline Weight gain and maintenance, $\mathrm{n}(\%)$ & $25(52)$ & $20(32)$ & \multirow{3}{*}{0.03} \\
\hline Weight loss, n (\%) & $18(38)$ & $35(55)$ & \\
\hline Missing values, $\mathrm{n}(\%)$ & $5(10)^{\#}$ & $8(13)^{*}$ & \\
\hline$A D L^{1}$, median change $[\mathrm{IQR}]$ & $8[5 ; 10]$ & $5[2 ; 10]$ & 0.22 \\
\hline Improved or maintained, $\mathrm{n}(\%)$ & $40(83)$ & $44(70)$ & \multirow{3}{*}{0.06} \\
\hline Deteriorated, $\mathrm{n}(\%)$ & $3(6)$ & $11(17)$ & \\
\hline Missing values, $\mathrm{n}(\%)$ & $5(11)^{\#}$ & $8(13)^{*}$ & \\
\hline Handgrip strength, mean change, kg. (SD) & $0.2(0.6)$ & $0(0.4)$ & 0.80 \\
\hline Improved or maintained, $\mathrm{n}(\%)$ & $29(60)$ & $32(50)$ & \multirow{3}{*}{0.35} \\
\hline Deteriorated, $\mathrm{n}(\%)$ & $14(29)$ & $23(37)$ & \\
\hline Missing values, $\mathrm{n}(\%)$ & $5(11)^{\#}$ & $8(13)^{*}$ & \\
\hline Mobility-tiredness ${ }^{2}$, mean change (SD) & $1.9(0.4)$ & $1.3(0.4)$ & 0.34 \\
\hline Less or unchanged fatigue, $\mathrm{n}(\%)$ & $38(79)$ & $47(74)$ & \multirow{3}{*}{0.67} \\
\hline More fatigue, n (\%) & $5(10.5)$ & $8(13)$ & \\
\hline Missing values, $\mathrm{n}(\%)$ & $5(10.5)^{\#}$ & $8(13)^{*}$ & \\
\hline Depression ${ }^{3}$, mean change (SD) & $-0.6(0.2)$ & $-0.7(0.4)$ & 0.78 \\
\hline Improved or maintained score, $\mathrm{n}(\%)$ & $37(77)$ & $42(67)$ & \multirow{3}{*}{0.23} \\
\hline Deteriorated, n (\%) & $6(13)$ & $13(20)$ & \\
\hline Missing values, $\mathrm{n}(\%)$ & $5(10)^{\#}$ & $8(13)^{*}$ & \\
\hline
\end{tabular}




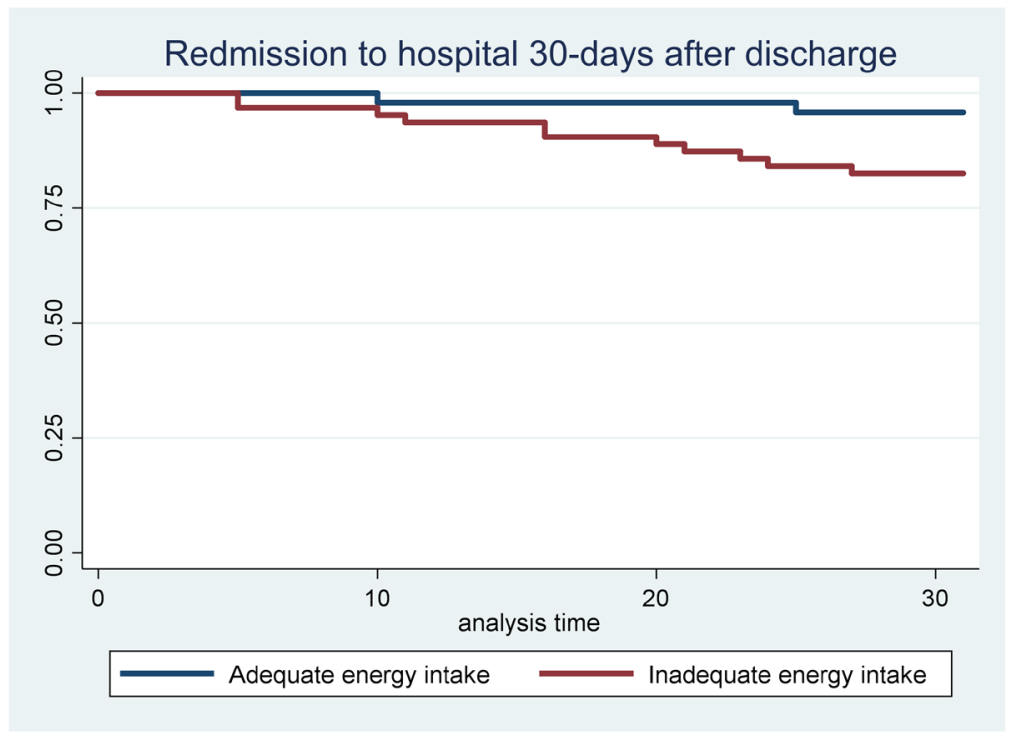

Figure 2. Risk of readmission 30 days after discharge in patients with adequate or inadequate energy intake two weeks after discharge.

Table 4. The risk of readmission to hospital and mortality.

\begin{tabular}{lcccccc}
\hline & AQ & IAQ & \multicolumn{2}{c}{ Crude estimates } & \multicolumn{2}{c}{$\begin{array}{c}\text { Estimates adjusted } \\
\text { for morbidity }\end{array}$} \\
\hline & $\mathrm{n}(\%)$ & $\mathrm{n}(\%)$ & HR $(95 \% \mathrm{CI})$ & $\mathrm{p}$-value & HR $(95 \% \mathrm{CI})$ & p-value \\
\hline 30-day readmission & $2(4)$ & $11(17)$ & $4.5(1-20.2)$ & 0.05 & $4.6(1-20.1)$ & 0.05 \\
90-day readmission & $11(17)$ & $17(27)$ & $1.6(0.7-3.6)$ & 0.25 & $1.6(0.7-3.6)$ & 0.25 \\
30-day mortality & 0 & 0 & - & - & - & - \\
90-day mortality & $1(2)$ & $8(13)$ & $6.4(0.8-51.7)$ & 0.08 & $7.2(0.9-58.9)$ & 0.06 \\
\hline
\end{tabular}

The risk of readmission to hospital and mortality 30 and 90-day after discharge. The participants are grouped according to adequate (AQ) or inadequate (IAQ) energy intake two weeks after discharge. Hazard ratio (HR), crude estimates and estimates adjusted for morbidity with 95\% CI.

\subsection{Mortality}

None of the 111 participants included at week two after discharge died within 30 days after discharge. At 90 days after discharge, nine participants had died; 1 in the AQ group and 8 in the IAQ group $(\mathrm{p}=0.06)($ Table 4$)$.

\section{Discussion}

This study is a secondary analysis including two intervention groups from a randomized clinical trial. The study identifies patient-reported factors affecting appetite and food intake early after discharge from hospital. The presence of "fatigue" and "eating all meals alone" led to failure to meet individual energy needs. Weight loss was experienced by more participants who did not meet their energy needs two weeks after discharge. The original RCT study showed that nutritional follow-up performed as home visit prevent deterioration of ADL function and readmission to hospital [20] [21]. This secondary analysis shows a trend towards 
more participants with deteriorated ADL functions when energy needs are not met two weeks after discharge. Participants with inadequate energy intake had higher rates of readmission to hospital 30 days after discharge.

It seems that older individuals' food intake early after discharge has long-term consequences for rehabilitation and health. Therefore, it is essential that the nutritional intervention initiated during the hospital stay continues directly after discharge and during subsequent months.

\subsection{Body Weight and ADL Function}

More participants with inadequate energy intake at an early stage after discharge lost body weight compared with participants with adequate energy intake.

Unintended weight loss in older adults means loss of muscle and ADL function [22] [23]. Loss of ADL function during disease and hospitalisation has long-term consequences such as problems with regaining functions and dependence on help in performing ADL [24] [25]. Therefore, prevention of disability and preservation of independence are of great clinical importance. The present study shows a trend towards maintained ADL function at two months after discharge in participants with adequate energy intake.

\subsection{Fatigue}

About half of the participants in this study reported fatigue during the first month after discharge from hospital. Despite the mobility-tiredness score did not detect difference between groups; patient-reported fatigue was more frequent among participants with inadequate energy intake. Furthermore, patient-reported fatigue during the first two weeks after discharge was associated with decreased energy intake simultaneously and later. Fatigue can lead to reduced energy intake and malnutrition; it affects daily activity patterns and leads to physical and functional inactivity [26] [27]. Fatigue may compromise adaptation to changed life situations after discharge from hospital (e.g. disease and loss of functions). Studies using the clinical phenotype of frailty including the fatigue component have found significant associations between frailty, malnutrition and reduced physical activity [28] [29] [30]. Health professionals must be aware that fatigue can be an early sign of deterioration in nutrition and health status among older malnourished and newly discharged individuals. Observation or a simple question about experience of fatigue should alert healthcare professionals' attention to nutritional problems. Early interventions may prevent aggravation of malnutrition and health problems. Individuals whose appetite is poor and who suffer from fatigue do not spontaneously ask for food or nutritional support. Health professionals who are in contact with older persons must take responsibility for detecting and handling the problem.

\subsection{Loneness and Eating with Family and Friends}

More than two thirds of the participants ate all meals alone, which is associated 
with lower energy intake [31]. Older people who live alone have a reduced number of daily meals, poorer appetite, lower daily food intake and a larger number of self-reported food problems than persons living in a family environment [32] [33].

Company, conversation and a pleasant atmosphere during mealtimes may encourage older individuals to eat more than they would have eaten if they were alone [6]. Widows are more likely to be at nutritional risk than those who live with another person or have divorced or have never married [34]. Recent loss of a spouse affects appetite and food intake negatively. Feelings of loneliness increase and alter the social meaning and daily routines associated with eating [31] [35].

\subsection{Promoting Factors}

In this study, almost all participants reported promoting factors to food intake, such as drinking additional oral nutritional supplements, eating with the family, visiting neighbours, preparing meals, going for a walk and having a good night's sleep. It is important for health professionals to collect and use this knowledge in order to encourage individuals to perform more health-promoting activities [36].

\subsection{The Home Carer}

The patient's pathway through the healthcare system especially that of the older individual who depends on help and support relies on cooperation between healthcare professionals from the hospital and community. Differences between community and hospital health care in terms of organisation and traditions may complicate and prevent a smooth and successful transfer. Most of the older adults in this study received daily help from home care facilities, nutritional support and meals on wheels. The participant's home carer was invited to participate in the nutritional counselling sessions together with the clinical dietitian with the purpose of providing support for including the individual diet plan in the older adult's daily living. Unfortunately, in our study, the home carer's adherence to the counselling sessions was poor, and we know little about the daily support provided by the home carer. There may be several reasons for this, including organisational issues, workload, routines, individual priorities and attitudes, and lack of knowledge about the consequences of disease-related malnutrition and the significance of nutritional support for the newly discharged older adult [37] [38] [39] [40].

\subsection{Readmission and Mortality}

Participants with poor energy intake had a higher risk of readmission to hospital at 30 days after discharge, but not at 90 days after discharge. One explanation for this may be that the intervention stopped at four weeks after discharge. Counselling sessions may encourage some participants to overcome poor appetite and eat according to their nutritional needs, but this may change after termination of the support from the dietitian. The home carer is evidently not able to continue nutritional support. 


\subsection{Limitations}

It is a major limitation to the study that the self-reported measures of food intake and inhibitory factors to food intake is collected by the dietitian who also provided the intervention. Another limitation to the study is that data only includes self-reported information about the participants' adherence or non-adherence to the diet plan.

After discharge, the diet plan had to be simple for the participants to follow, so only energy needs and not protein needs were included in the diet plan. This is also a limitation to the study. Despite these limitations the participants' reports on inhibitory factors to food intake provided us with information about barriers to food intake after disease and discharge from hospital.

During hospital stay, the patients' individual daily intake of calories and protein was recorded by the nursing staff, but data collection on food intake in the homes of older people is complex and was beyond the scope of this study. Participants who reported that they followed the diet plan fully were registered as having adequate intake of energy, whereas partly or not following the plan was registered as inadequate energy intake. It can be discussed whether this classification is correct.

International nutritional scientists recommend that hospitalized patients at nutritional risk have a daily nutritional intake of at least $75 \%$ of their requirements [41] and a recent randomised study confirms significant health outcomes in medical patients with a daily intake of $75 \%$ or more [42].

\subsection{External Validity}

The study population comprise a wide range of medical conditions, similar to those seen in patients admitted to other geriatric wards. Patients who suffered from cognitive impairment were not included, given the need for cognitive skills to comply with the intervention. Consequently, the results cannot be directly generalised to the entire older population. On the other hand, the results are valid for acutely hospitalised, malnourished older adults who were cognitively intact and used to live independently and alone. The results may also be valid for other adults who live with a partner.

\section{Conclusion}

The presence of the patient-reported factors "fatigue" and "eating all meals alone" after discharge affected food intake negatively during the following weeks. This led to failure to meet individual energy needs followed by loss of body weight and readmission to hospital 30 days after discharge. Health professionals must be aware of fatigue as an early sign of deterioration in nutrition and health status, and initiate nutritional interventions to prevent the aggravation of nutrition and health problems.

\section{Relevance for Clinical Practice}

The older adult's pathway through the health care system relies on cooperation 
between health care professionals from hospital and primary health care. It is essential that the nutritional intervention initiated during the hospital stay continues directly after discharge and during subsequent months. Health professionals must be aware of older individuals who eat all meals alone and/or report fatigue. Observation or a simple question about experience of fatigue should alert healthcare professionals' attention to nutritional problems. Early interventions may prevent aggravation of malnutrition and health problems. All health professionals who are in contact with older persons must take responsibility for detecting and handling the problem. Almost all older adults can point out individual factors that promote their appetite and food intake. Health professionals must identify these factors and provide individual support to the older adult.

\section{Acknowledgements}

Thanks to clinical dietician Rikke Elkjær Nielsen for performing the intervention.

\section{Conflict of Interest}

The authors declare no conflicts of interest regarding the publication of this paper.

\section{References}

[1] Holst, M., Yifter-Lindgren, E., Surowiak, M., Nielsen, K., Mowe, M., Carlsson, M., et al. (2013) Nutritional Screening and Risk Factors in Elderly Hospitalized Patients: Association to Clinical Outcome? Scandinavian Journal of Caring Sciences, 27, 953-961. https://doi.org/10.1111/scs.12010

[2] Kaiser, M.J., Bauer, J.M., Ramsch, C., Uter, W., Guigoz, Y., Cederholm, T., et al. (2010) Frequency of Malnutrition in Older Adults: A Multinational Perspective Using the Mini Nutritional Assessment. Journal of the American Geriatrics Society, 58, 1734-1738. https://doi.org/10.1111/j.1532-5415.2010.03016.x

[3] Charlton, K.E., Nichols, C., Bowden, S., Lambert, K., Barone, L., Mason, M., et al. (2010) Older Rehabilitation Patients Are at High Risk of Malnutrition: Evidence from a Large Australian Database. The Journal of Nutrition, Health and Aging, 14, 622-628. https://doi.org/10.1007/s12603-010-0307-3

[4] Giezenaar, C., Chapman, I., Luscombe-Marsh, N., Feinle-Bisset, C., Horowitz, M. and Soenen, S. (2016) Ageing Is Associated with Decreases in Appetite and Energy Intake-A Meta-Analysis in Healthy Adults. Nutrients, 8, pii: E28. https://doi.org/10.3390/nu8010028

[5] Carlsson, P., Tidermark, J., Ponzer, S., Soderqvist, A. and Cederholm, T. (2005) Food Habits and Appetite of Elderly Women at the Time of a Femoral Neck Fracture and after Nutritional and Anabolic Support. Journal of Human Nutrition and Dietetics, 18, 117-120. https://doi.org/10.1111/j.1365-277X.2005.00594.x

[6] Wysokinski, A., Sobow, T., Kloszewska, I. and Kostka, T. (2015) Mechanisms of the Anorexia of Aging: A Review. Age, 37, 9821. https://doi.org/10.1007/s11357-015-9821-x

[7] Nieuwenhuizen, W.F., Weenen, H., Rigby, P. and Hetherington, M.M. (2010) Older Adults and Patients in Need of Nutritional Support: Review of Current Treatment 
Options and Factors Influencing Nutritional Intake. Clinical Nutrition, 29, 160-169. https://doi.org/10.1016/j.clnu.2009.09.003

[8] Callen, B.L. and Wells, T.J. (2003) Views of Community-Dwelling, Old-Old People on Barriers and Aids to Nutritional Health. Journal of Nursing Scholarship, 35, 257-262. https://doi.org/10.1111/j.1547-5069.2003.00257.x

[9] Stanga, Z., Allison, S., Vandewoude, M. and Schneider, S.M. (2011) Nutrition in the Elderly. In: Sobotka, L., Ed., Basics in Clinical Nutrition, Publishing House Galén, Prague, 540-563.

[10] MacIntosh, C., Morley, J.E. and Chapman, I.M. (2000) The Anorexia of Aging. Nutrition, 16, 983-995. https://doi.org/10.1016/S0899-9007(00)00405-6

[11] Guigoz, Y., Lauque, S. and Vellas, B.J. (2002) Identifying the Elderly at Risk for Malnutrition: The Mini Nutritional Assessment. Clinics in Geriatric Medicine, 18, 737-757. https://doi.org/10.1016/S0749-0690(02)00059-9

[12] Vellas, B., Guigoz, Y., Garry, P.J., Nourhashemi, F., Bennahum, D., Lauque, S., et al. (1999) The Mini Nutritional Assessment (MNA) and Its Use in Grading the Nutritional State of Elderly Patients. Nutrition, 15, 116-122. https://doi.org/10.1016/S0899-9007(98)00171-3

[13] Nordic Counsel of Ministers (2014) Nordic Nutrition Recommendations 2012: Integrating Nutrition and Physical Activity. https://doi.org/10.26530/OAPEN_483279

[14] Pedersen, J., Pedersen, P. and Damsgaard, E. (2015) Nutritional Follow-Up after Discharge of Malnourished Geriatric Patients-Design of a Randomized Clinical Study. Journal of Aging Research \& Clinical Practice, 4, 92-101.

[15] Shah, S., Vanclay, F. and Cooper, B. (1989) Improving the Sensitivity of the Barthel Index for Stroke Rehabilitation. Journal of Clinical Epidemiology, 42, 703-709. https://doi.org/10.1016/0895-4356(89)90065-6

[16] Norman, K., Stobaus, N., Gonzalez, M.C., Schulzke, J.D. and Pirlich, M. (2011) Hand Grip Strength: Outcome Predictor and Marker of Nutritional Status. Clinical Nutrition, 30, 135-142. https://doi.org/10.1016/j.clnu.2010.09.010

[17] Sheikh, J.I. (1986) Geriatric Depression Scale: Recent Evidence and Development of a Shorter Version. In: Brink, T.L., Ed., Clinical Gerontology: A Guide to Assessment and Intervention, Hawtorn Press, New York, 165-173. https://doi.org/10.1300/J018v05n01_09

[18] Djernes, J.K., Kvist, E., Olesen, F., Munk-Jorgensen, P. and Gulmann, N.C. (2004) Validation of a Danish Translation of Geriatric Depression Scale-15 as a Screening Tool for Depression among Frail Elderly Living at Home. Ugeskrift for Læger, 166, 905-909.

[19] Avlund, K., Kreiner, S. and Schultz-Larsen, K. (1996) Functional Ability Scale for the Elderly: A Validation Study. European Journal of Public Health, 6, 35-42. https://doi.org/10.1093/eurpub/6.1.35

[20] Pedersen, J.L., Pedersen, P.U. and Damsgaard, E.M. (2016) Early Nutritional Follow-Up after Discharge Prevents Deterioration of ADL Functions in Malnourished, Independent, Geriatric Patients Who Live Alone-A Randomized Clinical Trial. The Journal of Nutrition, Health and Aging, 20, 845-853.

https://doi.org/10.1007/s12603-015-0629-2

[21] Pedersen, J., Pedersen, P. and Damsgaard, E. (2017) Nutritional Follow-Up after Discharge Prevents Readmission to Hospital: A Randomized Clinical Trial. Journal of Nutrition, Health and Aging, 21, 75-82. https://doi.org/10.1007/s12603-016-0745-7 
[22] Wakabayashi, H. and Sakuma, K. (2014) Rehabilitation Nutrition for Sarcopenia with Disability: A Combination of Both Rehabilitation and Nutrition Care Management. Journal of Cachexia, Sarcopenia and Muscle, 5, 269-277. https://doi.org/10.1007/s13539-014-0162-x

[23] Sorbye, L.W., Schroll, M., Finne Soveri, H., Jonsson, P.V., Topinkova, E., Ljunggren, G., et al. (2008) Unintended Weight Loss in the Elderly Living at Home: The Aged in Home Care Project (AdHOC). The Journal of Nutrition, Health and Aging, 12, 10-16. https://doi.org/10.1007/BF02982158

[24] Covinsky, K.E., Pierluissi, E. and Johnston, C.B. (2011) Hospitalization-Associated Disability: She Was Probably Able to Ambulate, But I'm Not Sure. JAMA, 306, 1782-1793. https://doi.org/10.1001/jama.2011.1556

[25] Boyd, C.M., Landefeld, C.S., Counsell, S.R., Palmer, R.M., Fortinsky, R.H., Kresevic, D., et al. (2008) Recovery of Activities of Daily Living in Older Adults after Hospitalization for Acute Medical Illness. Journal of the American Geriatrics Society, 56, 2171-2179. https://doi.org/10.1111/j.1532-5415.2008.02023.x

[26] Martin, P., Bishop, A., Poon, L. and Johnson, M.A. (2006) Influence of Personality and Health Behaviors on Fatigue in Late and Very Late Life. The Journals of Gerontology, Series B: Psychological Sciences and Social Sciences, 61, 161-166. https://doi.org/10.1093/geronb/61.3.P161

[27] Tennant, K.F., Takacs, S.E., Gau, J.T., Clark, B.C. and Russ, D.W. (2012) A Preliminary Study of Symptomatic Fatigue in Rural Older Adults. Aging Clinical and EXperimental Research, 24, 324-330.

[28] Fried, L.P., Tangen, C.M., Walston, J., Newman, A.B., Hirsch, C., Gottdiener, J., et al. (2001) Frailty in Older Adults: Evidence for a Phenotype. The Journals of Gerontology. Series A, Biological Sciences and Medical Sciences, 56, M146-M156. https://doi.org/10.1093/gerona/56.3.M146

[29] Bartali, B., Frongillo, E.A., Bandinelli, S., Lauretani, F., Semba, R.D., Fried, L.P., et al. (2006) Low Nutrient Intake Is an Essential Component of Frailty in Older Persons. The Journals of Gerontology. Series A, Biological Sciences and Medical Sciences, 61, 589-593. https://doi.org/10.1093/gerona/61.6.589

[30] Peterson, M.J., Giuliani, C., Morey, M.C., Pieper, C.F., Evenson, K.R., Mercer, V., et al. (2009) Physical Activity as a Preventative Factor for Frailty: The Health, Aging, and Body Composition Study. The Journals of Gerontology. Series A, Biological Sciences and Medical Sciences, 64, 61-68. https://doi.org/10.1093/gerona/gln001

[31] de Boer, A., Ter Horst, G.J. and Lorist, M.M. (2013) Physiological and Psychosocial Age-Related Changes Associated with Reduced Food Intake in Older Persons. Ageing Research Reviews, 12, 316-328. https://doi.org/10.1016/j.arr.2012.08.002

[32] Ramic, E., Pranjic, N., Batic-Mujanovic, O., Karic, E., Alibasic, E. and Alic, A. (2011) The Effect of Loneliness on Malnutrition in Elderly Population. Medical Archives, 65, 92-95.

[33] Ferry, M., Sidobre, B., Lambertin, A. and Barberger-Gateau, P. (2005) The Solinut Study: Analysis of the Interaction between Nutrition and Loneliness in Persons Aged over 70 Years. The Journal of Nutrition, Health and Aging, 9, 261-268.

[34] Wham, C.A., The, R.O., Robinson, M. and Kerse, N.M. (2011) What Is Associated with Nutrition Risk in Very Old Age? The Journal of Nutrition, Health and Aging, 15, 247-251. https://doi.org/10.1007/s12603-010-0304-6

[35] Dahlberg, L., Andersson, L., McKee, K.J. and Lennartsson, C. (2015) Predictors of Loneliness among Older Women and Men in Sweden: A National Longitudinal Study. Aging and Mental Health, 19, 409-417. 
https://doi.org/10.1080/13607863.2014.944091

[36] Pedersen, P.U., Kuosma, K. and Hundrup, Y.A. (2014) Mealtime Assistance and Identification of Eating Difficulties Prevent Unintented Weight Loss in Nursing Home Residents-A Controlled Trial. Journal of Nursing Education and Practice, 4, 33-42. https://doi.org/10.5430/jnep.v4n11p33

[37] Mowe, M., Bosaeus, I., Rasmussen, H.H., Kondrup, J., Unosson, M., Rothenberg, E., et al. (2008) Insufficient Nutritional Knowledge among Health Care Workers? Clinical Nutrition, 27, 196-202. https://doi.org/10.1016/j.clnu.2007.10.014

[38] Fletcher, A. and Carey, E. (2011) Knowledge, Attitudes and Practices in the Provision of Nutritional Care. The British Journal of Nursing, 20, 615-616, 618-620. https://doi.org/10.12968/bjon.2011.20.10.615

[39] Bauer, S., Halfens, R.J. and Lohrmann, C. (2015) Knowledge and Attitudes of Nursing Staff towards Malnutrition Care in Nursing Homes: A Multicentre Cross-Sectional Study. The Journal of Nutrition, Health and Aging, 19, 734-740. https://doi.org/10.1007/s12603-015-0535-7

[40] Håkonsen, S.J., Bjerrum, M., Bygholm, A., Kjelgaard, H.H. and Pedersen, P.U. (2018) The Routines, Knowledge and Attitudes towards Nutrition and Documentation of Nursing Staff in Primary Healthcare: A Cross-Sectional Study. Journal of Community \& Public Health Nursing, 4, 1-8.

[41] Bounoure, L., Gomes, F., Stanga, Z., Keller, U., Meier, R., Ballmer, P., et al. (2016) Detection and Treatment of Medical Inpatients with or At-Risk of Malnutrition: Suggested Procedures Based on Validated Guidelines. Nutrition, 32, 790-798. https://doi.org/10.1016/j.nut.2016.01.019

[42] Schuetz, P., Fehr, R., Baechli, V., Geiser, M., Deiss, M., Gomes, F., et al. (2019) Individualised Nutritional Support in Medical Inpatients at Nutritional Risk: A Randomised Clinical Trial. The Lancet, 393, 2312-2321. https://doi.org/10.1016/S0140-6736(18)32776-4 


\section{Appendix}

\section{Data Collection during Intervention}

\section{Patient ID:}

Type of intervention

Home carer participates?

Is the diet plan followed?

Inhibitory factors to eating:

Gastro-intestinal problems

Mouth/teeth problems

Eat alone

Fatigue

Sadness

Other inhibitory factors

Support from the home carer?

Describe:

Promoting factors

If yes: Which:

New initiatives and agreements: $\mid$

L_ $\mid($ yes $=1$, no $=2)$

L_ $($ yes $=1$, no $=2$, partly $=3)$

|_ $\mid($ yes $=1$, no $=2)$

L_ $\mid($ yes $=1$, no $=2)$

|_ $\mid($ yes $=1$, no $=2)$

L_ $($ yes $=1$, no $=2)$

|_ $\mid($ yes $=1$, no $=2)$

$\left|\_\right|($yes $=1$, no $=2)$

L_ $\mid($ yes $=1$, no $=2)$

$\left|\_\right|($yes $=1$, no $=2)$ 